\title{
Immature monocytes contribute to cardiopulmonary bypass-induced acute lung injury by generating inflammatory descendants
}

\author{
Zhichen Xing, ${ }^{1,2}$ Junyan Han, ${ }^{3,4}$ Xing Hao, ${ }^{1,2}$ Jinhong Wang, ${ }^{1,2}$ Chunjing Jiang, ${ }^{1,2}$ \\ Yu Hao, ${ }^{3,4}$ Hong Wang, ${ }^{1,2}$ Xueying $\mathrm{Wu}^{3,4}$ Liwei Shen, ${ }^{5,6}$ Xiaojun Dong, ${ }^{5,6}$ \\ Tong Li, ${ }^{3,4}$ Guoli Li, ${ }^{3,4}$ Jianping Zhang, ${ }^{3,4}$ Xiaotong Hou, ${ }^{1,2}$ Hui Zeng ${ }^{3,4}$
}

- Additional material is published online only. To view please visit the journal online (http://dx.doi.org/10.1136/ thoraxjn-2015-208023)

For numbered affiliations see end of article.

\section{Correspondence to} Professor Hui Zeng, Institute of Infectious Diseases, Beijing Ditan Hospital, Capital Medical University, Jingshundongjie 8, Chaoyang District, Beijing 100015, China; zenghui@ ccmu.edu.cn and

Professor Xiaotong Hou, Department of Cardiopulmonary Bypass, Center for Cardiac Intensive Care, Beijing Anzhen Hospital, Capital Medical University, No. 2 Anding Road, Chaoyang District, Beijing 100029. China:

houxiaotong_2013@163.com

ZX, JH, and XH contributed equally to this paper.

Received 4 November 2015 Revised 23 August 2016 Accepted 24 August 2016 Published Online First 22 September 2016

\section{ABSTRACT}

Background As immune regulatory and effector cells, monocytes play an important role in the bloodextracorporeal circuit contact-related acute lung injury in patients undergoing cardiopulmonary bypass (CPB). However, circulating monocytes are phenotypically and functionally heterogeneous, so we characterised how immature monocytes affect acute lung injury induced by CPB.

Methods The identification and dynamic changes in monocyte subsets were monitored by flow cytometry in patients undergoing CPB and in a rat model of CPB. The differentiation and migration of monocyte subsets were explored by in vitro cultures and adoptive transfer in the CPB rat model.

Results We observed a dramatic increase of two monocyte subsets in the peripheral blood of patients undergoing $\mathrm{CPB}$, involving tumour necrosis factor (TNF)$\alpha$-producing, mature intermediate CD14 ${ }^{\text {high }} \mathrm{CD} 16^{+}$ monocytes and a novel immature CD14 ${ }^{\text {low }}$ CD $16^{-}$subset. The immature $\mathrm{CD} 14^{\text {low }} \mathrm{CD} 16^{-}$monocytes possessed limited ability for TNF- $\alpha$ production, and failed to suppress T-cell proliferation mediated by T-cell receptor signalling. However, these immature cells were highly proliferative and could differentiate into TNF- $\alpha$ producing, mature $\mathrm{CD} 14^{\text {high }} \mathrm{CD} 16^{+}$monocytes. In the rat model of $\mathrm{CPB}$, we further demonstrated that $\mathrm{CPB}$ induced migration of immature monocytes into the lungs, either from the bone marrow or from the spleen. Moreover, we confirmed the hypothesis that immature subsets could contribute to CPB-induced acute lung injury by giving rise to TNF- $\alpha$ producing descendants. Conclusions The immature CD14 ${ }^{\text {low }}$ CD $16^{-}$monocytes might contribute to blood-circuit contact-induced acute lung injury by generating TNF- $\alpha$-producing, mature monocytes. New strategies based on monocyte manipulation could be a promising therapeutic approach for minimising CPB-related lung injury.

\section{INTRODUCTION}

Cardiopulmonary bypass (CPB) has been widely used clinically to support temporarily total heart and/or lung function during cardiac surgery. ${ }^{1} 2$ Despite development of the techniques, $\mathrm{CPB}$ exposes the blood to the large synthetic, non-endothelial cell surface of the extracorporeal circuit. Such blood-circuit contact may trigger

\section{Key messages}

What is the key question?

- How do different subsets of monocytes contribute to cardiopulmonary bypass induced acute lung injury or pulmonary dysfunction?

What is the bottom line?

- Human monocytes are phenotypically and functionally heterogeneous, and play different roles in the inflammatory response.

\section{Why read on?}

- We demonstrated that the immature CD14 ${ }^{\text {low }}{ }^{2} 16^{-}$subset generates downstream inflammatory $\mathrm{CD} 14^{\text {high }} \mathrm{CD} 16^{+}$descendants, which might provide novel targets for perioperative lung protection by manipulating monocyte subsets at different checkpoints.

severe systemic and local inflammatory responses, which subsequently can cause a number of clinical complications. ${ }^{3}{ }^{4}$ It is acknowledged that almost all patients undergoing $\mathrm{CPB}$ have different degrees of acute lung injury (ALI) or pulmonary dysfunction. ${ }^{4}{ }^{5}$ About $2 \%$ of adult patients develop acute respiratory distress syndrome (ARDS) or even acute respiratory failure with a high risk of mortality $(15-72 \%){ }^{67}$

Multiple factors have been demonstrated to be involved in CPB-induced ALI. Among these factors, monocytes and macrophages have drawn considerable attention due to their important roles in immune responses and $\mathrm{ALI},{ }^{8}{ }^{9}$ because systemic inflammatory responses can trigger monocyte trafficking into injured organs. ${ }^{10} 11$ After being recruited to sites of tissue injury and inflammation, monocytes can regulate local immune responses by acting as a key source of proinflammatory cytokines and functioning as precursors for macrophages and dendritic cells. ${ }^{12} 13$

Recently, monocyte heterogeneity prompted us to investigate the pathogenesis of CPB-induced lung injury. Early studies demonstrated that human circulating monocytes are phenotypically and functionally heterogeneous, and can be subdivided into 
$\mathrm{CD} 14^{\text {high }} \mathrm{CD} 16^{-}$classic inflammatory monocytes and $\mathrm{CD} 14^{+} \mathrm{CD} 16^{+}$resident subsets. ${ }^{12}{ }^{14-17}$ Other studies reported that among $\mathrm{CD} 14^{+} \mathrm{CD} 16^{+}$monocytes, a subset with a $\mathrm{CD} 14^{\text {high }} \mathrm{CD} 16^{+}$phenotype (termed as intermediate monocytes) was more closely correlated with the pathogenesis of many inflammatory diseases, exhibited a high capacity for production of tumour necrosis factor (TNF)- $\alpha$, and regulated immune responses. ${ }^{18} 19 \mathrm{CD} 14^{\text {low }} \mathrm{CD} 16^{+}$monocytes (named non-classical monocytes) are smaller and less granular, and express higher levels of the C-X-C chemokine receptor (CX3CR1), ${ }^{15}$ patrol the vascular endothelium, and are involved in the innate surveillance of local tissues. ${ }^{15} 20$

The nomenclature for monocyte subsets was mainly based on studies of circulating monocytes. ${ }^{21} 22$ Recently, the bone marrow and the spleen have been identified as two critical reservoirs of monocytes. A large fraction of immature monocytes in the reservoirs are immature cells with a $\mathrm{CD} 14^{+/ \text {low }} \mathrm{CD} 16^{-}$phenotype, ${ }^{23}$ which might be released into the peripheral blood under stress conditions. In the present study, we determined whether and how these immature monocytes affect CPB-induced ALI. We found that although blood-circuit contact could cause transient sequestration of monocytes, the immature $\mathrm{CD} 14^{\text {low }} \mathrm{CD} 16^{-}$ subset, and TNF- $\alpha$-producing $\mathrm{CD} 14^{\text {high }} \mathrm{CD} 16^{+}$monocytes, dramatically increased in the peripheral blood of patients with $\mathrm{CPB}$. We further applied a rat model of $\mathrm{CPB}$, and hypothesised that immature monocytes might migrate from their reservoirs into the lungs after the $\mathrm{CPB}$, and contribute to $\mathrm{CPB}$-induced ALI by generating mature TNF- $\alpha$-secreting descendants.

\section{MATERIALS AND METHODS \\ Patients}

Fifty patients (24 men and 26 women, aged $37-71$ years) undergoing cardiac surgery with CPB were enrolled at Beijing Anzhen Hospital, Capital Medical University. All human blood samples were collected after written informed consent was obtained, and the study conformed to the tenets of the Declaration of Helsinki. For the analyses of monocyte subset kinetic changes, blood samples from patients were collected into EDTA vacuum tubes after the onset of anaesthesia (pre), and on postoperative days $0,1,3,5$ and 7 after CPB. Detailed information of all patients, including primary diseases and indications, is described in the online supplementary materials.

\section{CPB model}

Adult male Sprague-Dawley rats (350-400 g) were obtained from the Vital River Laboratories (Beijing, China). The rat CPB model was established using a dedicated small animal ventilator, extracorporeal circulation machine, and pipelines. The model is described in detail in the online supplementary material.

\section{Flow cytometry analysis and cell sorting}

Cells from peripheral blood, bone marrow, spleen, lung or bronchoalveolar lavage fluid (BALF) were stained with the indicated markers, and monocyte subsets were identified and detected by flow cytometry. Monocyte subsets from patients and rats were sorted by FACS Aria II (BD, Palo Alto, California, USA). Detailed information is described in the online supplementary materials.

\section{Carboxyfluorescein-diacetate succinimidyl ester staining and cell proliferation assay}

T-cell proliferation was determined by measuring changes in fluorescence using carboxyfluorescein-diacetate succinimidyl ester (CFSE) labelling, as described previously. ${ }^{24}$

\section{TNF- $\alpha$ RNA and protein measurements}

The TNF- $\alpha$ mRNA level of different monocyte subsets from patients or rats was determined using real-time PCR. The secretion of TNF- $\alpha$ of human or rat monocyte subsets was detected using an ELISA or Cytometric Bead Array (CBA). Detailed descriptions of these procedures are provided in the online supplementary material.

\section{In vitro labelling of $\mathrm{CD} 43^{\text {low }}$ monocytes and adoptive transfer}

Rat CD $43^{\text {low }}$ monocytes were sorted with flow cytometry (FACS Aria II), then labelled with dioctadecyl tetramethylindotricarbocyanine iodide (DiR; Life Technologies, Carlsbad, California, USA). The $\mathrm{DiR}^{+}$monocytes were injected into healthy rats through the vena orbitalis posterior plexus 1 hour before CPB.

\section{In vivo labelling of CD43 ${ }^{\text {high }}$ monocytes with fluorescent latex microspheres}

Anaesthetised rats were intravenously injected with Flouresbrite Plain $0.5 \mu \mathrm{m}$ microspheres $(2.5 \%$ solids $\mathrm{w} / \mathrm{v}$; Polyscience, Niles, Illinois, USA) through the left femoral vein to label CD $43^{\text {high }}$ monocytes, referring to the methods for labelling mouse Ly $6 \mathrm{c}^{\text {high }}$ subsets. ${ }^{25}$ After 24 hours, the CPB rat model was created.

\section{Statistical analysis}

Data are reported as mean \pm SEM of values obtained from at least three independent experiments. Significant Differences between healthy control and $\mathrm{CPB}$ models, or between $\mathrm{CPB}$ models and the splenectomy $\mathrm{CPB}$ models were compared using Student's $t$ test. Analysis of variance (ANOVA) was applied to analyse the expression differences of surface and functional molecules, and TNF- $\alpha$ protein or RNA expression of different monocyte subsets. During the follow-up of patients and the rat model, because the subjects in the study were observed at different times, and to determine the contribution of individual subjects and times to the difference across cell subtype kinetic changes, the repeated measurement data analysis of variance methodology was used and was followed by post hoc Bonferroni analyses. If the data were not symmetric, the Greenhouse-Geisser correction was used. $\mathrm{p}<0.05$ was considered statistically significant.

\section{RESULTS \\ Emergence of CD14 ${ }^{\text {low }} \mathrm{CD} 16^{-}$immature Mo0 monocytes after CPB}

We found that the monocytes rapidly and dramatically increased within one day after $\mathrm{CPB}$ in patients undergoing $\mathrm{CPB}$ (figure $1 \mathrm{~A}$ and online supplementary figure S1). To monitor the changes in monocyte subsets, blood monocytes were subdivided into three subsets: CD14 ${ }^{\text {high }} \mathrm{CD} 16^{-}$(Mo1), CD14 ${ }^{\text {high }} \mathrm{CD} 16^{+}$(Mo2) and $\mathrm{CD}_{14}{ }^{\text {low }} \mathrm{CD} 16^{+}(\mathrm{Mo3})$, as previously described ${ }^{24}$ (figure $1 \mathrm{~B}$ ). Importantly, we noticed that a subset of monocytes with a $\mathrm{CD} 14^{\text {low }} \mathrm{CD} 16^{-}$phenotype (named as Mo0, figure $1 \mathrm{~B}, \mathrm{C}$ ) rapidly emerged in the peripheral blood of patients undergoing CPB (from $3 \%$ preoperatively to $25 \%$ at 0 days post CPB). Compared with Mo1 monocytes, Mo0 monocytes were more morphologically immature (figure 1D) and expressed similar levels of HLA-DR, toll-like receptor (TLR4), and CD64 as expressed by the Mo1 subsets, but lower levels of CD86 (figure $1 \mathrm{E}$ and online supplementary figure S2). However, compared with the Mo2 and Mo3 subsets, the Mo0 monocytes expressed lower levels of HLA-DR and CD86 (figure 1E and online supplementary figure S2). 
Figure 1 Identification of human blood $\mathrm{CD} 14^{\mathrm{low}} \mathrm{CD} 16^{-}$immature monocytes induced by cardiopulmonary bypass (CPB). (A) Dynamic changes of total monocyte numbers. The peripheral blood from patients receiving CPB was collected at the indicated times, and total monocytes were analysed by flow cytometry combined with a Trucount Tube. The repeated measurement data analysis of variance (ANOVA) methodology was applied and was followed by post hoc Bonferroni analysis. Data are expressed as the median and IQR for each time point of 10 individuals and are representative of 10 individuals. (B and C) Ideograph (B) and representative flow cytometry (C) analyses of monocytes. The fresh peripheral blood from the patients was collected, stained with specific antibodies, and then lysed with red blood cell lysing buffer. According to the expression pattern of CD14 and CD16, human monocytes were divided into $\mathrm{CD} 14^{\mathrm{low}} \mathrm{CD} 16^{-}(\mathrm{MoO})$, CD14 ${ }^{\text {high }} \mathrm{CD} 16^{-}$(Mo1), CD14 ${ }^{\text {high }} \mathrm{CD} 16^{+}$ (Mo2), and CD14 ${ }^{\text {low }} \mathrm{CD} 16^{+}$(Mo3) subsets. (D) Morphology of peripheral monocyte subsets (Wright-Giemsa staining) from healthy controls (upper panel) and patients undergoing CPB (lower panel). Three or four monocyte subsets were sorted by FACS Aria II and Cytospin preparation of different monocytes for Wright-Giemsa staining. Magnification, 1000x, scale bar, $20 \mu \mathrm{m}$. (E) The mean fluorescence intensity (MFI) of HLA-DR, TLR-4, CD86 and CD64 in four monocyte subsets after 1 day from patients receiving CPB was analysed by flow cytometry. Mean values are indicated $(n=10)$. ANOVA was applied to analyse the expression difference of surface and functional molecules of different monocyte subsets.
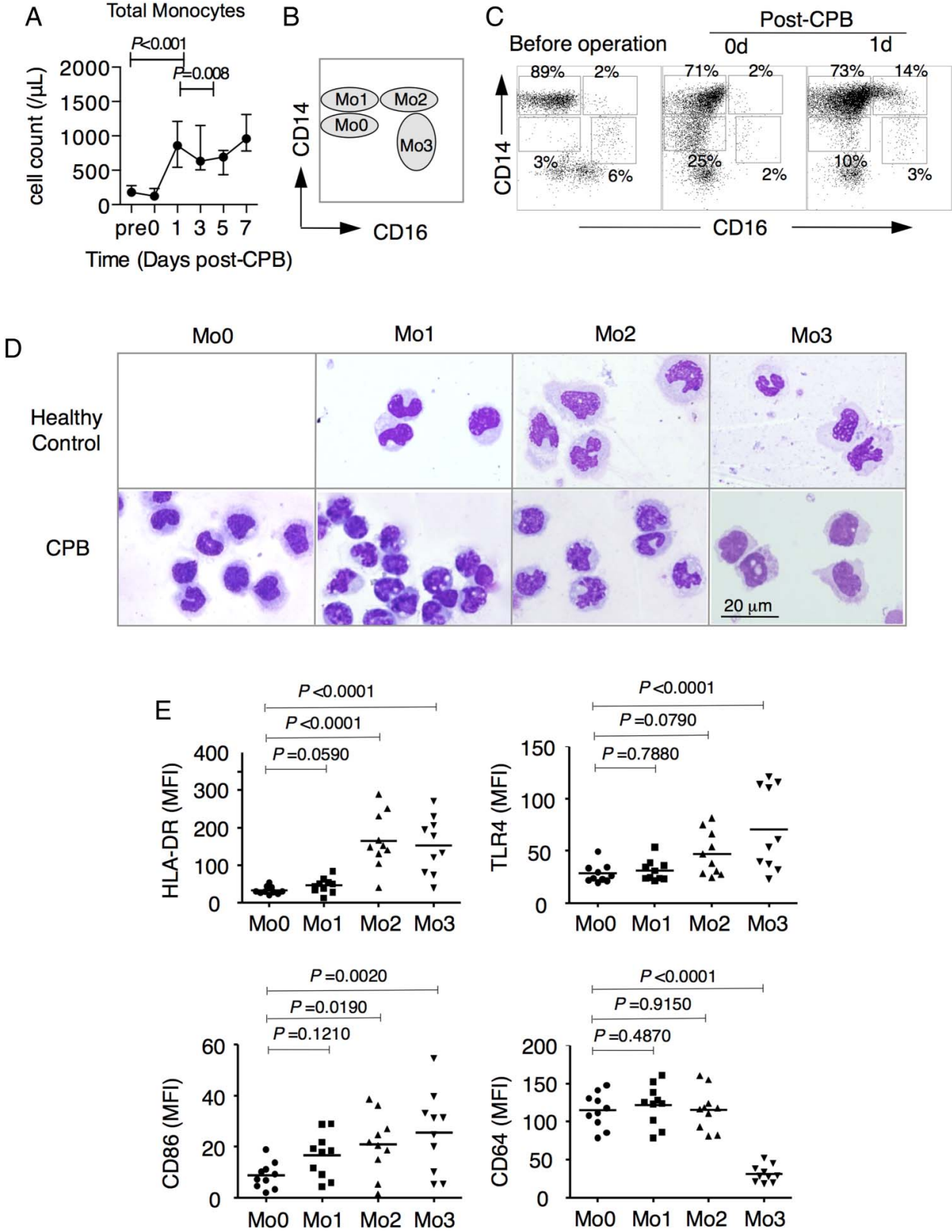

Immature Mo0 monocytes gave rise to mature, cytokine-secreting Mo2 monocytes

Given that Mo0 monocytes were immature, we tested whether the differentiation process was blocked. We found that about $10 \%$ of $\mathrm{Mo} 0$ monocytes from patients with CPB expressed nuclear protein Ki67, which was significantly higher than other subsets (figure 2A,B). This observation indicated that this population was more proliferative than other subsets. Next, we performed in vitro culture of whole blood samples from patients 1 day after $\mathrm{CPB}$ and pre $\mathrm{CPB}$, and observed a rapid decrease in the percentage of $\mathrm{Mo} 0$ monocytes, along with a dramatically increased percentage of Mo2 monocytes within $16 \mathrm{~h}$ (figure 2C, $\mathrm{D}$; online supplementary figure $\mathrm{S} 3 \mathrm{~A}, \mathrm{~B})$. In addition to the above, in vitro differentiation results, we found a decreased percentage of $\mathrm{Mo} 0$ monocytes in the peripheral blood of patients at 1 day after cessation of CPB. Meanwhile, consistent with a previous report of patients with haemodialysis, ${ }^{26}$ we found a dramatic $8-10$-fold increase $(2.22 \% \pm 0.23 \%$ vs $18.98 \%$ $\pm 2.24 \%$; $<<0.0001$; figure $2 \mathrm{E}$ ) in the number of $\mathrm{Mo} 2$ monocytes (figure 2E), which might reflect in vivo differentiation of $\mathrm{Mo} 0$ subsets into $\mathrm{Mo} 2$ monocytes. The kinetic change of percentage and numbers of different monocyte subsets for each patient was shown and the same trend was observed in all patients (see online supplementary figure S4A,B). The expression of HLA-DR on Mo0 and Mo1 monocytes decreased after $\mathrm{CPB}$ and gradually returned at 7 days post $\mathrm{CPB}$ (see online supplementary figure S5A,B).

Notably, CBA and RT-PCR analyses detected higher levels of TNF- $\alpha$ protein and mRNA in Mo2 monocytes (figure 2F,G), which suggested that immature $\mathrm{Mo} 0$ monocytes might contribute to $\mathrm{CPB}$-induced inflammatory responses by generating mature, cytokine-secreting Mo2 monocytes.

\section{CPB induced accumulation of immature and mature} monocytes into the lungs

Because it is very difficult to investigate whether blood-circuit, contact-induced migration of immature monocytes occurred from their reservoirs into the lungs in patients with $\mathrm{CPB}$, we 
A

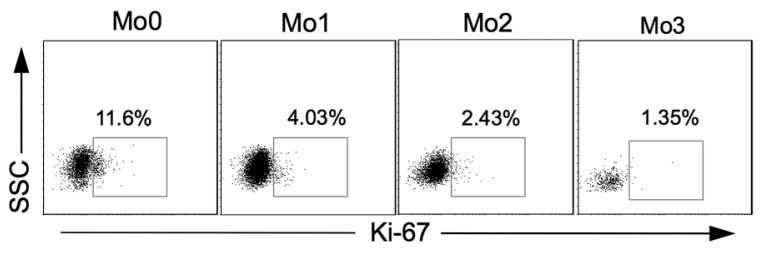

B
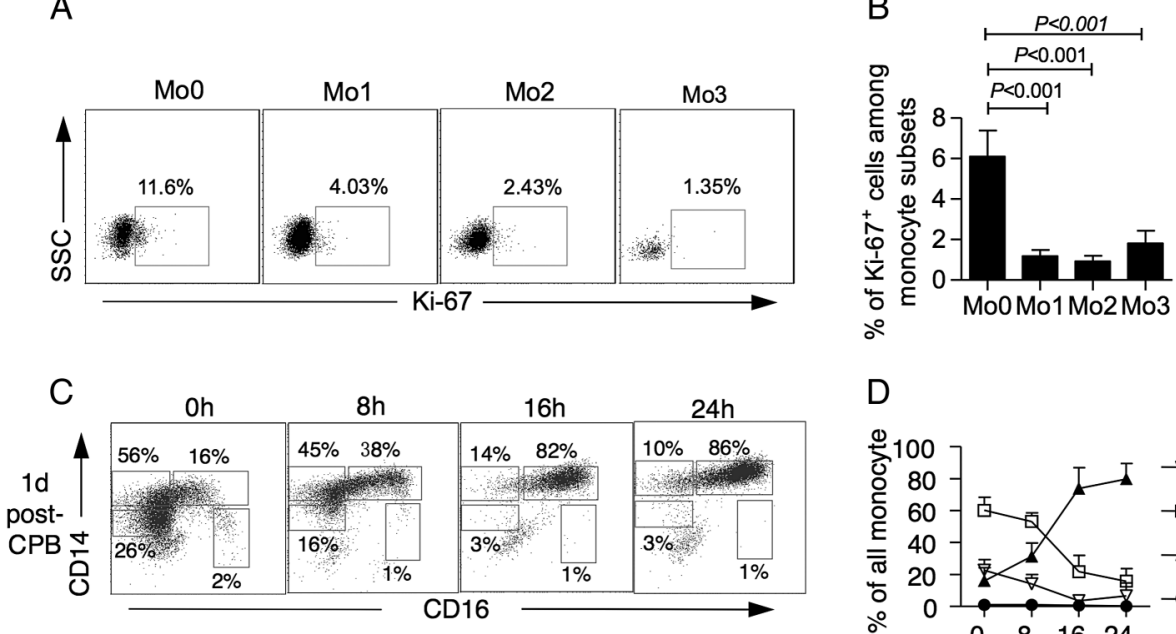

D

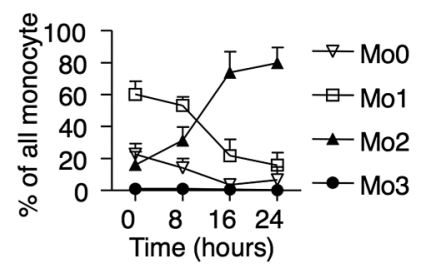

Mo3
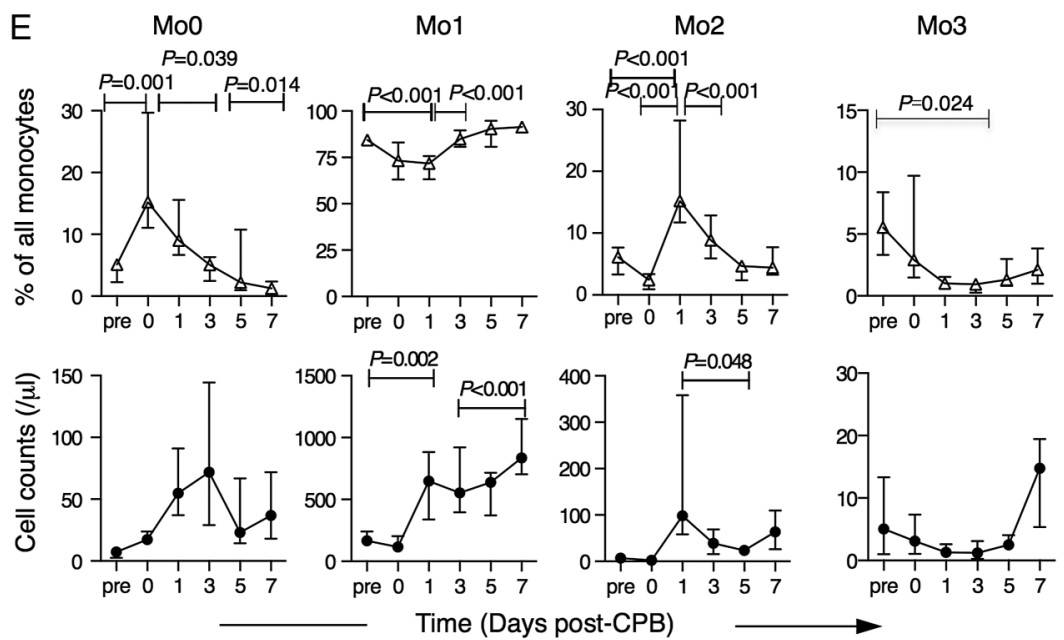

$\mathrm{F}$
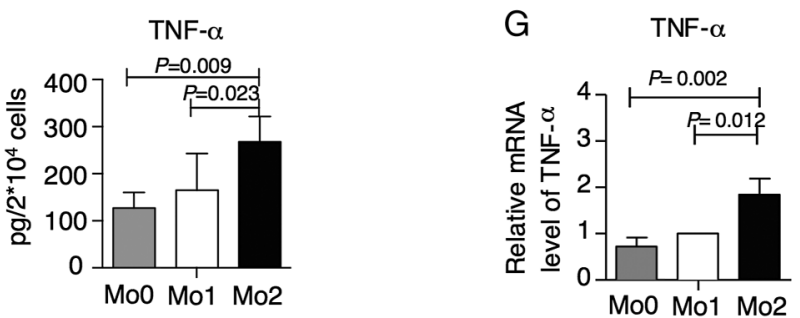

Figure 2 Proliferation and differentiation of $\mathrm{CD} 14^{\mathrm{low}} \mathrm{CD} 16^{-}$immature monocytes. (A) Representative flow cytometry analyses combined with intracellular staining of Ki-67 expression in different monocyte subsets at 1 day after cardiopulmonary bypass (CPB). (B) The percentage of Ki-67-positive cells among Mo0, Mo1, Mo2 and Mo3 subsets from patients at 1 day post CPB. Analysis of variance (ANOVA) was used to analyse the differences among these groups $(n=10)$. ( $C$ and $D)$ The whole peripheral blood samples from patients at 1 day post CPB were cultured for indicated times using an in vitro differentiation assay. Representative scatter diagrams of flow cytometry (C) and kinetic changes of the percentages of different monocyte subsets (D) are shown from 10 individuals. The repeated measurement data ANOVA methodology was applied and was followed by post hoc Bonferroni analysis. Repeated measures ANOVA showed that the main effect of the percentage of different monocyte subsets on the kinetic change of monocyte subsets was significant $(p<0.001)$. Post hoc comparisons indicated that the percentages of Mo0 and Mo1 significantly decreased (Mo0: $0-8$ hours, $\mathrm{p}=0.014 ; 0-16$ hours, $\mathrm{p}<0.001 ; 0-24$ hours, $\mathrm{p}<0.001 ; 8-16$ hours, $\mathrm{p}=0.007$; for Mo1: $0-8$ hours, $\mathrm{p}=0.028$; $0-16$ hours, $p<0.001 ; 0-24$ hours, $p<0.001 ; 8-16$ hours, $p<0.001$; and $8-24$ hours, $p<0.001)$, and the percentages of Mo2 gradually increased $(0-8$ hours, $p<0.001 ; 0-16$ hours, $p<0.001 ; 0-24$ hours, $p<0.001 ; 8-16$ hours, $p<0.001$; and $16-24$ hours, $p<0.001$ ). Data are expressed as the mean \pm SEM of 10 individuals for each time point and are representative of 10 independent experiments. $(E)$ The dynamic changes of percentage and numbers $(n=10)$ of circulating monocyte subsets in the patients before CPB and post CPB at indicated times. The peripheral blood from patients receiving CPB was collected at the indicated times, and monocyte subsets were analysed by flow cytometry combined with a Trucount Tube. Data are expressed as the median and IQR of indicated individuals for each time point. The repeated measurement data ANOVA methodology was applied and followed by post hoc analysis. The repeated measures ANOVA did not find a significant effect of time on the kinetic changes of different monocytes ( $p=1.000$ ). (F) Expression of tumour necrosis factor (TNF)- $\alpha$ protein by Mo0, Mo1 and Mo2 subsets was determined using Cytometric Bead Array ( $n=5)$. (G) Expression levels of TNF- $\alpha$ mRNA in monocyte subsets of patients were analysed with real-time PCR. Data are shown as mean \pm SEM of five individuals and are representative of five independent experiments. 
used a rat CPB model. In this model, histological analyses showed that leukocytes were entrapped in the lung capillaries (figure 3A). We also observed an increase in total proteins and elevated cell counts of whole leukocytes, neutrophils and monocytes in BALF with a peak at 6 hours post CPB (figure 3B,C), which indicated that $\mathrm{CPB}$ caused ALI in these animals.

According to previous studies, ${ }^{27}{ }^{28}$ rat monocytes were subdivided into immature $\mathrm{CD} 172 \mathrm{a}^{+} \mathrm{CD} 43^{\text {low }}\left(\mathrm{CD} 43^{\text {low }}\right)$ and relatively mature $\mathrm{CD} 172 \mathrm{a}^{+} \mathrm{CD} 43^{\text {high }}\left(\mathrm{CD} 43^{\text {high }}\right)$ subsets (figure 3D-F, Wright-Giemsa staining). In healthy rats, immature CD $43^{\text {low }}$ monocytes accounted for $\sim 90 \%$ of monocytes in the bone marrow, while monocytes in the peripheral blood, spleen, lungs and BALF contained higher frequencies of CD $43^{\text {high }}$ monocytes (figure 3G). ELISA and real-time PCR analysis detected higher levels of TNF- $\alpha$ protein and mRNA in mature CD43 ${ }^{\text {high }}$ monocytes from peripheral blood and the lungs of $\mathrm{CPB}$ rats (figure $3 \mathrm{H}, \mathrm{I}$ ), which suggested that mature $\mathrm{CD} 43^{\text {high }}$ monocytes, rather than immature CD $43^{\text {low }}$ monocytes, might be a major source of TNF- $\alpha$ in response to blood circuit contact.

Consistent with the results from patients undergoing $\mathrm{CPB}$, the frequency of the immature $\mathrm{CD} 43^{\text {low }}$ subset dramatically increased after the $\mathrm{CPB}$ operation and gradually returned to normal levels after 24 hours (figure 4A). Furthermore, we observed a rapid and transient increase in immature CD $43^{\text {low }}$ monocytes in the lung tissues, with a peak at 3 hours post $\mathrm{CPB}$ (figure $4 \mathrm{~B}$ and online supplementary figure S6). In BALF, the absolute numbers of CD43 ${ }^{\text {high }}$ monocytes increased and reached a plateau at 3 hours after ceasing CPB (figure 4B). Thus, immature and mature monocytes might migrate into the lungs in response to $\mathrm{CPB}$ challenge.

\section{Migration of $C D 43^{\text {low }}$ and $C D 43^{\text {high }}$ monocytes from the bone marrow and spleen in rats with CPB}

It has been reported that in addition to the bone marrow, the spleen is also a reservoir for monocytes, ${ }^{11}$ 29-31 Within 3-6 hours after ceasing $\mathrm{CPB}$, the numbers of $\mathrm{CD} 43^{\text {low }}$ monocytes declined in the bone marrow and spleen to $50-60 \%$ of the baseline levels (figure 4C), which further suggests that immature monocytes were mobilised and migrated from bone marrow and spleen. By contrast, a significant decrease in CD $43^{\text {high }}$ monocytes was only observed in the spleen, and not in the bone marrow (figure 4C), which indicated that the majority of mature monocytes mobilised into the lungs were from the spleen.

To further confirm the notion, we performed $\mathrm{CPB}$ on rats with splenectomy. The number of CD43 $3^{\text {low }}$ monocytes in the lung tissues decreased by $\sim 20 \%$, while the number of CD $43^{\text {high }}$ monocytes in BALF decreased more than 70\% (figure 4D). There was no significant difference in monocyte subsets between the sham-operated control rats and healthy control rats (figure 4D). Thus, bone marrow might be the major source of $\mathrm{CD} 43^{\text {low }}$ monocytes, while the spleen might be involved in releasing $\mathrm{CD} 43^{\text {low }}$ and $\mathrm{CD} 43^{\text {high }}$ subsets, but predominantly $\mathrm{CD} 43^{\text {high }}$. Consistent with a decreased number of monocytes in the lungs, ALI was alleviated in rats with splenectomy, as shown by a decreased protein concentration of BALF and less leukocyte infiltration into lung tissues (figure 4E,F).

\section{CD43 ${ }^{\text {low }}$ monocytes migrated and contributed to $\mathrm{CD} 43^{\text {high }}$ monocytes in the lungs}

Similar to human Mo0 monocytes, we found that rat CD $43^{\text {low }}$ monocytes could differentiate into CD43 $3^{\text {high }}$ monocytes in whole blood culture (figure $5 \mathrm{~A}$ ). Since $\mathrm{CD} 43^{\text {low }}$ monocytes can migrate into the lungs and rapidly differentiate, we wondered whether the immature monocyte could differentiate in vivo and enhance the number of CD43 ${ }^{\text {high }}$ monocytes in the lungs. To test this possibility, we sorted CD43 ${ }^{\text {low }}$ monocytes from normal rats, labelled them with DiR, and adoptively transferred them into recipient rats (described in figure 5B). At 6 hours after ceasing $\mathrm{CPB}$, these recipient rats showed an increase in the percentage and number of $\mathrm{DiR}^{+} \mathrm{CD} 43^{\text {low }}$ monocytes in the lungs (figure $5 \mathrm{C}, \mathrm{D}$ ). Later, the number of $\mathrm{DiR}^{+} \mathrm{CD} 43^{\text {low }}$ monocytes started to decline, along with a slight increase in the number of $\mathrm{DiR}^{+} \mathrm{CD} 43^{\text {high }}$ monocytes in the lungs. Subsequently, we observed a dramatic increase in the $\mathrm{DiR}^{+} \mathrm{CD} 68^{+}$macrophages in the lungs and BALF at 18 hours after cessation of CPB (figure $5 \mathrm{D})$. These results indicated that immature monocyte subsets could further differentiate into mature subsets and increase the number of $\mathrm{CD} 43^{\text {high }}$ monocytes in the lungs after a $\mathrm{CPB}$ challenge.

\section{Influx of $\mathrm{CD} 43^{\text {high }}$ subsets into the lungs}

Next, we tried to directly traffic the migration of $\mathrm{CD} 43^{\text {high }}$ monocytes. However, we could not harvest sufficient CD $43^{\text {high }}$ monocytes from the spleen for adoptive transfer. Since fluorescent LX microspheres have been used to track selectively the migration of mouse $\mathrm{Gr} 1^{\text {low }}$ monocytes (equivalent to rat CD $43^{\text {high }}$ monocytes) from the peripheral blood to the injured tissues ${ }^{25}$ we selectively labelled rat $\mathrm{CD} 43^{\text {high }}$ monocytes by intravenous injection of fluorescent LX microspheres. In the preliminary experiments, we found that all $\mathrm{LX}^{+}$cells were in the CD $43^{\text {high }}$ subset at 24 hours after injection and could be observed in the blood and lungs for $>7$ days (figure $6 \mathrm{~A}$ and online supplementary figure S7). Thus, the rats underwent $\mathrm{CPB}$ (outlined in figure 6B) at 24 hours after injection. Within 3 hours post $\mathrm{CPB}$, we found that the number of $\mathrm{LX}^{+} \mathrm{CD} 43^{\text {high }}$ monocytes sharply decreased in peripheral blood, but increased in the lung tissues, which suggested that $\mathrm{LX}^{+} \mathrm{CD} 43^{\text {high }}$ monocytes migrate from the blood into the lungs (figure 6C). Furthermore, we observed an increase in $\mathrm{LX}^{+} \mathrm{CD} 43^{\text {high }}$ monocytes as well as $\mathrm{LX}^{+} \mathrm{CD} 68^{+}$macrophages in BALF at 24 hours post $\mathrm{CPB}$ (see online supplementary figure $\mathrm{S} 8$ ), which suggested that $\mathrm{CD} 43^{\text {high }}$ monocytes might have moved into the alveolar cavity and differentiated into macrophages. When we performed the same procedures with the rats with splenectomy, the influx of $\mathrm{LX}^{+} \mathrm{CD} 43^{\text {high }}$ monocytes decreased by $\sim 50 \%$ in the lungs and about fivefold in the BALF (figure 6D). This finding further supported the notion that splenic $\mathrm{CD} 43^{\text {high }}$ monocytes migrated into the lung tissues after CPB.

\section{DISCUSSION}

Although a number of technological innovations and pharmaceutical interventions have led to progress in perioperative lung protection, CPB-induced ALI or ARDS is still considered to be a serious complication. ${ }^{7}$ In the present study, we characterised the distinct roles of monocyte subsets in CPB-induced ALI. We reported a dramatic and selective increase of two monocyte subsets in the peripheral blood of patients undergoing $\mathrm{CPB}$ involving the mature inflammatory $\mathrm{CD} 14^{\text {high }} \mathrm{CD} 16^{+} \mathrm{Mo} 2$ subset that functions as a major source of inflammatory cytokine TNF- $\alpha$, and the immature $\mathrm{CD} 14^{\text {low }} \mathrm{CD} 16^{-} \mathrm{Mo} 0$ subset that contributes to the generation of downstream inflammatory subsets. Using a rat model of CPB-induced ALI, we found that inflammatory monocytes and immature monocytes could migrate into the lung from the bone marrow and spleen. More importantly, immature $\mathrm{CD} 14^{\text {low }} \mathrm{CD} 16^{-}$monocytes contributed to ALI by generating their TNF-producing mature descendants.

Higher levels of TNF- $\alpha$ in BALF have been considered as a possible predictor for pulmonary dysfunction after cardiac 
surgery of patients undergoing $\mathrm{CPB} .{ }^{32}$ In the present study, we showed that the human $\mathrm{CD} 14{ }^{\text {high }} \mathrm{CD} 16^{+}$subset and rat CD $43^{\text {high }}$ monocytes expressed higher TNF- $\alpha$ mRNA than other monocyte subsets after $\mathrm{CPB}$, which indicated that inflammatory monocytes might be an important source of TNF- $\alpha$ in $\mathrm{CPB}$-induced aseptic inflammatory responses. The importance of $\mathrm{CD} 14^{+} \mathrm{CD} 16^{+}$monocytes in inflammation and tissue injury is also well documented in reports of laboratory and clinical studies. $^{12} \quad 18 \quad 33 \quad 34$ These cells are considered as inflammatory monocytes, because they express a higher level of HLA-DR, have higher ability of phagocytosis, produce more proinflammatory cytokines and chemokines such as TNF- $\alpha$, interleukin 6 , interferon $\gamma$, macrophage inflammatory protein $1 \alpha$ and
$1 \beta,{ }^{19} 3435$ and most importantly, are expanded in many inflammatory disorders. Mouse blood and splenic Ly $6 c^{\text {low }}$ monocytes, the counterpart of human $\mathrm{CD} 14^{+} \mathrm{CD} 16^{+}$monocytes, express higher TNF- $\alpha$ than Ly $6 c^{\text {high }}$ monocytes. ${ }^{30}$

Compared with circulating $\mathrm{CD} 14^{+} \mathrm{CD} 16^{+}$monocytes, the $\mathrm{CD} 14^{\text {low }} \mathrm{CD} 16^{-} \mathrm{Mo} 0$ subset usually resides in the bone marrow and spleen. ${ }^{23}$ The increase of this immature subset in the circulation indicates blood-circuit contact-enhanced emigration of immature monocytes from their reservoirs. Our study further increases our knowledge of monocyte subsets, especially during disease conditions. The Mo0 subset differed from the classical Mo1 subset. The Mo0 subset was morphologically more immature, had a lower level of CD14 and CD86, had a higher proliferative ability,
A

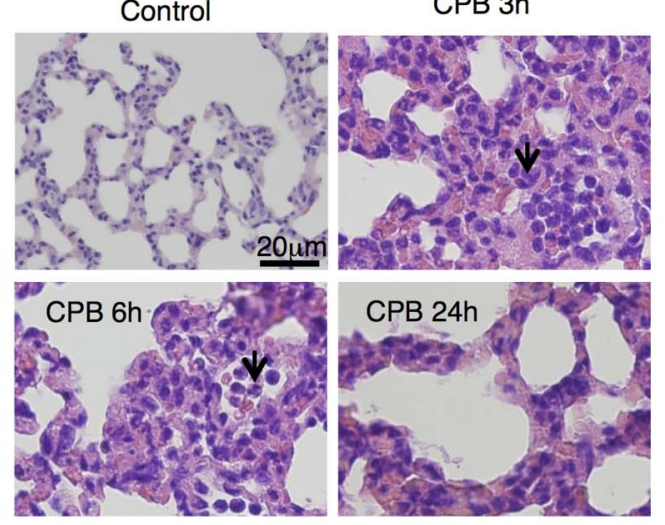

$\mathrm{B}$

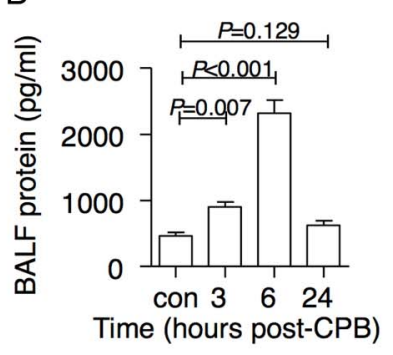

D

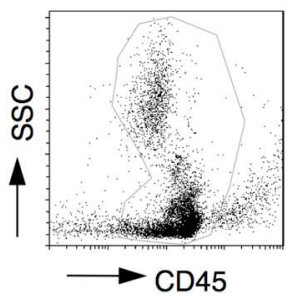

C

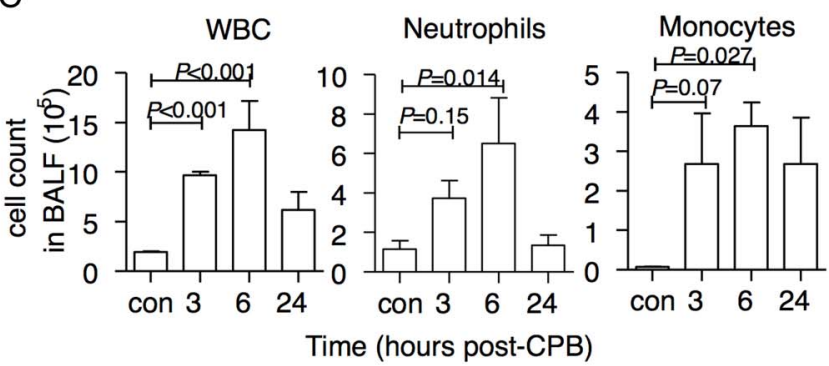

E
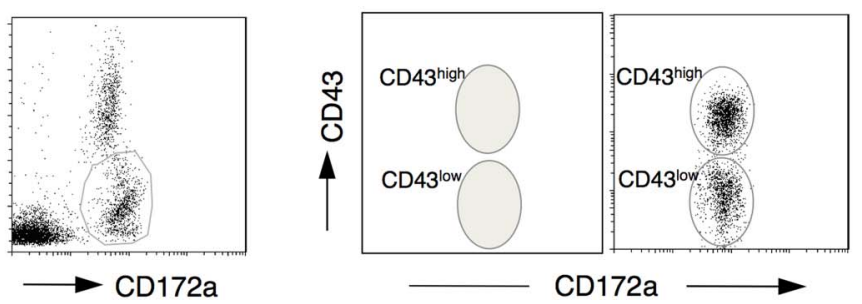

Figure 3 Cardiopulmonary bypass (CPB) induced acute lung injury in rats, and identification of rat monocyte subsets. (A) Representative histological image (H\&E staining) of lung sections from the control group, and the 6 hours and 24 hours post-CPB groups. Magnification, 400x, bar, $20 \mu \mathrm{m}$. (B) Total protein concentration in bronchoalveolar lavage fluid (BALF) from rats with CPB was analysed using the Pierce BCA Protein Assay Kit ( $n=3$ at the indicated times). (C) White blood cell (WBC), neutrophils and monocytes count in BALF at indicated times from rats with CPB were analysed by flow cytometry combined with haematometry ( $n=3$ at the indicated points). ( $D$ and $E$ ) Representative flow cytometric profiles of rat monocyte subsets in the peripheral blood as defined by the expression of CD172a and CD43. Rat CD172a ${ }^{+}$monocytes were divided into CD43 $3^{\text {low }}$ and CD43 ${ }^{\text {high }}$ monocytes. (F) Cytospin preparations of sorted CD43 ${ }^{\text {low }}$ and CD43 ${ }^{\text {high }}$ monocytes from the bone marrow, the peripheral blood, the spleen, and the lungs of healthy rats after Wright-Giemsa staining. Magnification, 1000x, scale bar, $20 \mu \mathrm{m}$. (G) Distribution percentages of CD43 ${ }^{\text {low }}$ and CD43 $3^{\text {high }}$ monocytes in bone marrow, peripheral blood, spleen, lung tissues, and BALF of normal rats $(n=5)$. (H) A total of $2 \times 10^{4} C D 43^{\text {low }}$ and $\mathrm{CD} 43^{\text {high }}$ monocytes in the peripheral blood, lung tissues, and alveolar lavage fluid from model rats at 3 hours post CPB were sorted, cultured with lipopolysaccharide $(1 \mathrm{pg} / \mathrm{mL}$ ) in medium (1640 RPMI with $10 \% \mathrm{FBS})$ for 3 hours, and the supernatant was collected and analysed using a rat ELISA kit $(n=5)$. (I) Expression levels of tumour necrosis factor (TNF)- $\alpha$ mRNA in sorted CD43 ${ }^{\text {low }}$ and CD43 ${ }^{\text {high }}$ monocytes in the peripheral blood, lung tissues, and alveolar lavage fluid from control rats or model rats at 3 hours post CPB were measured by real-time PCR $(n=3)$. 


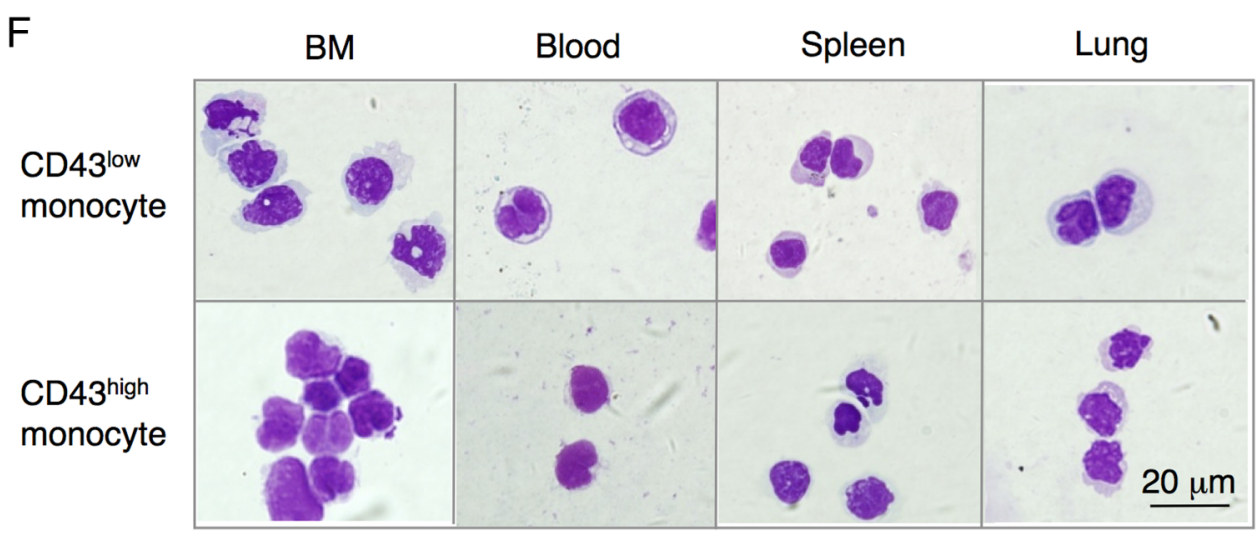

G

control rat

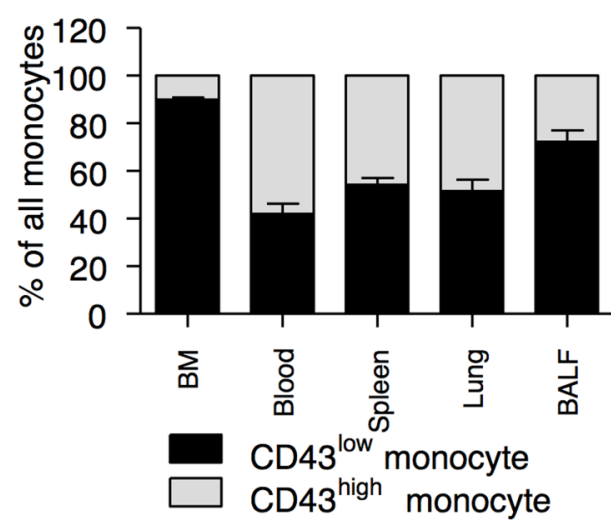

$\mathrm{H}$

TNF- $\alpha$

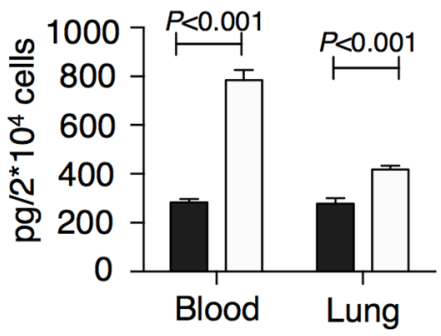

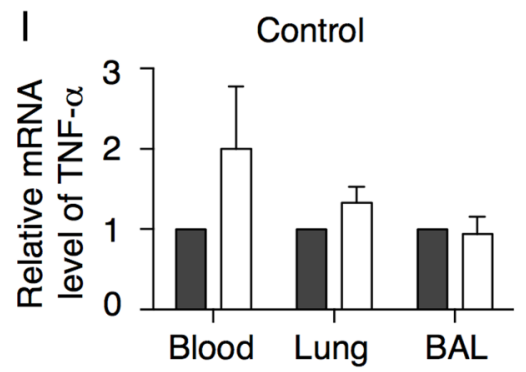

Figure 3 Continued

and had a lower capacity of TNF- $\alpha$ production. In a previous study, a fraction of CD14 HLA-DR ${ }^{\text {low } /-}$ immature monocytes with immunosuppressive capacity were identified as monocytic myeloid-derived suppressor cells (M-MDSCs). ${ }^{36}$ Despite sharing a similar phenotype with monocytic MDSCs that are found in patients with leukaemia or cancer, ${ }^{36}{ }^{37} \mathrm{Mo} 0$ monocytes from patients undergoing $\mathrm{CPB}$ promoted rather than inhibited T-cell receptor (TCR)-induced T-cell proliferation (see online supplementary figure S9), which indicated that Mo0 monocytes were distinct from M-MDSCs and might still be capable of facilitating adaptive responses. Notably, Mo0 monocytes possess limited ability for TNF- $\alpha$ production, thus they do not seem to contribute directly to inflammatory cytokine-induced tissue damage.
However, we found that these precursor cells could differentiate into mature TNF- $\alpha$-producing monocytes in response to aseptic inflammatory stimuli. This differentiation process from $\mathrm{Mo} 0$ to Mo2 monocytes could occur in the peripheral blood, as indicated by in vitro culture of whole blood samples from patients; or in situ in the lungs after being recruited into the lungs, as supported by in vivo adoptive transfer of $\mathrm{DiR}^{+} \mathrm{CD} 43^{\text {low }}$ monocytes in the rat $\mathrm{CPB}$ model. The latter finding is consistent with the recent finding that murine $\mathrm{Ly}-6 \mathrm{C}^{+1}$ high monocytes, the counterparts to human $\mathrm{CD} 14^{+} \mathrm{CD} 16^{-} \mathrm{Mo} 1$ monocytes, could locally differentiate into Ly-6C $\mathrm{C}^{-/ \mathrm{low}}$ monocytes, macrophages or inflammatory DCs after being recruited into the site of inflammation. ${ }^{12}$ Moreover, unlike circulating monocytes from healthy humans that usually terminate the cell 


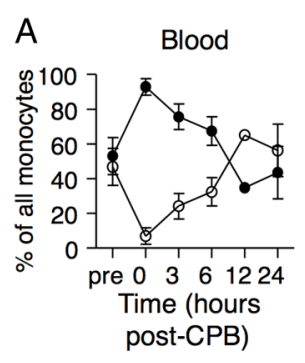

C
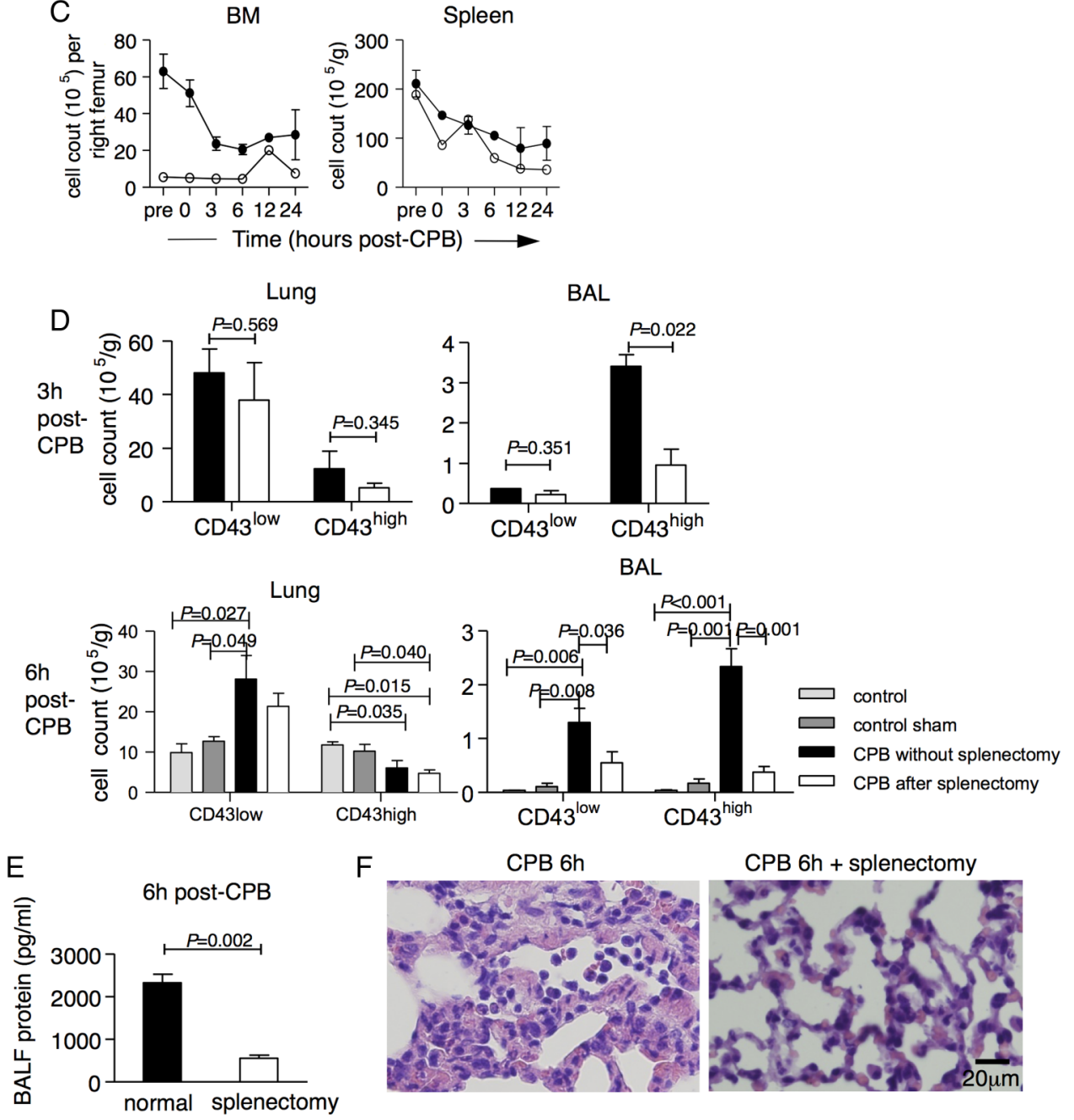

F

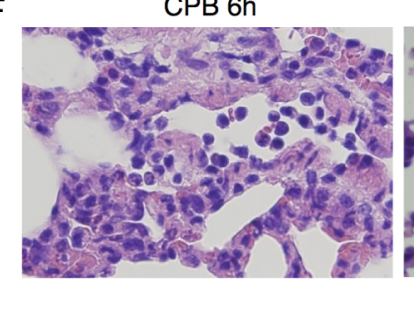

CPB $6 \mathrm{~h}+$ splenectomy

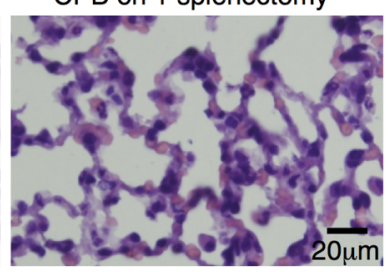

Figure 4 Dynamic post-cardiopulmonary bypass (CPB) changes of monocyte subsets in rats. (A) Dynamic changes of the percentages of CD43 ${ }^{\text {low }}$ and CD43 ${ }^{\text {high }}$ subsets in the peripheral blood before (pre: control rat) and post CPB at indicated times. (B) Dynamic changes of absolute cell counts of monocyte subsets in lung tissue and bronchoalveolar lavage fluid (BALF) at the indicated times $(n=3)$. (C) Dynamic changes of absolute cell counts of monocyte subsets in bone marrow (BM) and spleen at the indicated times $(n=3)$. (D) Cell counts of CD43 ${ }^{\text {low }}$ and $C D 43^{\text {high }}$ subsets in the lung and BALF at 3 hours and/or 6 hours post CPB in control rats, control sham rats, and CPB-treated rats with or without splenectomy ( $n=3$ ). Data are expressed as the mean \pm SEM of three animals and are representative of three independent experiments. (E) Alveolar protein concentration in the lungs of rats with or without splenectomy at 6 hours post CPB was analysed by the BCA protein assay kit $(n=3)$. (F) Respective H\&E staining of the lungs of the rats with or without splenectomy at 6 hours post CPB $(n=3)$. Magnification, 400x; scale bar, $20 \mu \mathrm{m}$.

cycle, Mo0 monocytes from patients undergoing $\mathrm{CPB}$ are highly proliferating cells, as indicated by the higher level of Ki-67. Given that Mo0 and Mo1 monocytes possess differentiation capacity, the excessive proliferation might enable these cells to generate a higher number of mature inflammatory monocytes, which subsequently cause more severe tissue injury.

The differentiation of immature monocyte subsets leads to a very important consequence involving the enhanced accumulation of TNF- $\alpha$-secreting mature monocytes in the lungs and
BALF. The local immune responses in the tissues could be regulated by the recruitment of leukocytes. ${ }^{11} 38$ The first step of monocyte migration is to migrate from their reservoirs in the bone marrow and spleen. ${ }^{1130} \mathrm{CPB}$ induces the release of monocytes from bone marrow, which then migrate into the lungs in the monkey model. ${ }^{39}$ In rats undergoing $\mathrm{CPB}$, bone marrow exhibited a rapid and dramatic decrease of immature CD $43^{\text {low }}$ monocytes, while the spleen showed a decrease in immature $\mathrm{CD} 43^{\text {low }}$ and mature CD $43^{\text {high }}$ monocytes. However, since 

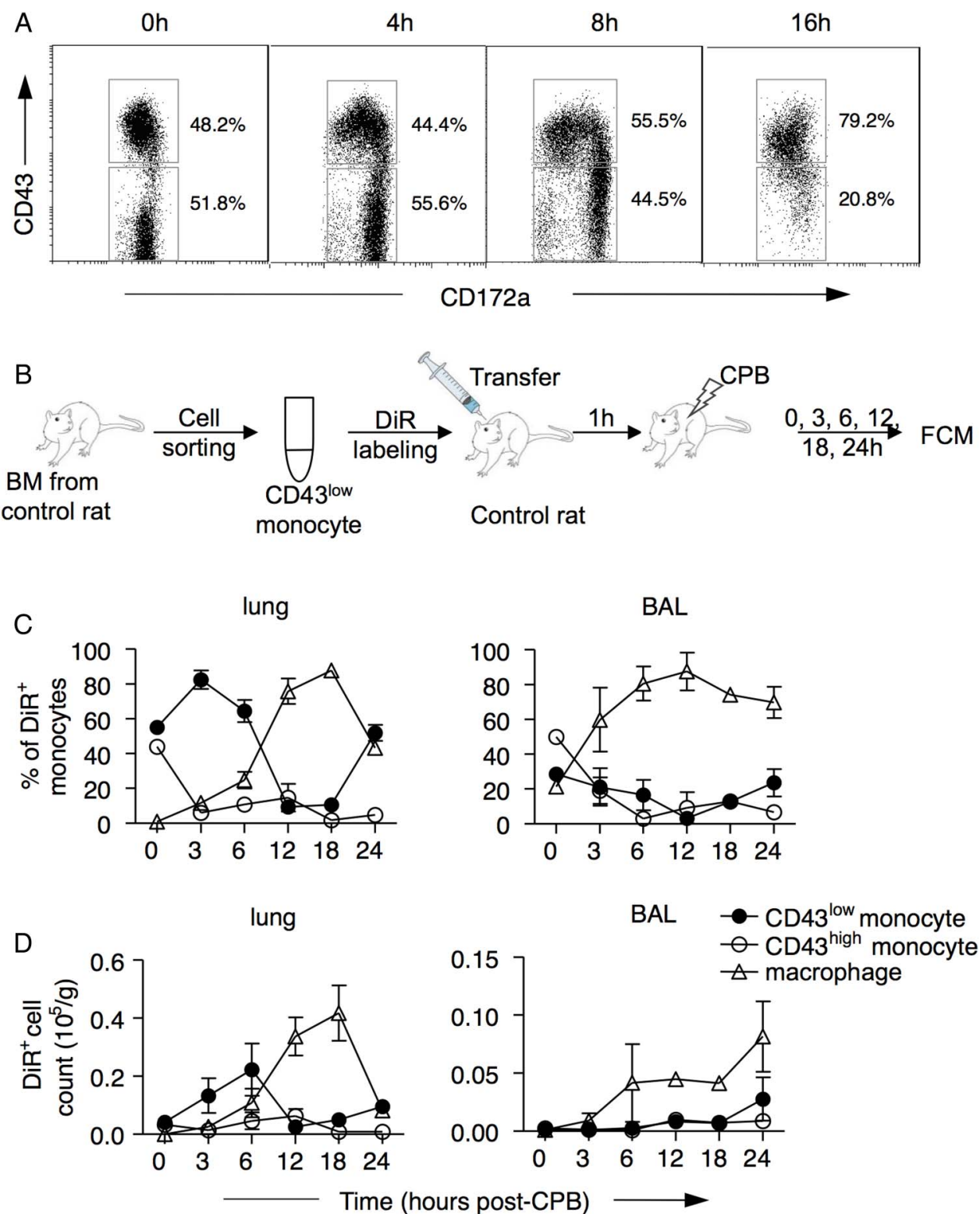

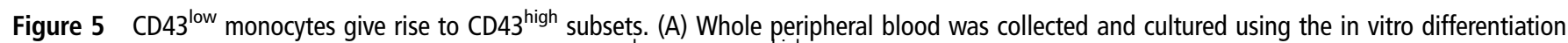
assay for the indicated times, and the percentages of CD43 ${ }^{\text {low }}$ and CD43 $3^{\text {high }}$ monocyte subsets were determined by flow cytometry. (B) Experimental schedule for adoptive transfer of DiR-labelled CD43 ${ }^{\text {low }}$ monocytes. CD43 ${ }^{\text {low }}$ monocytes were sorted by FACS Aria II from bone marrow (BM) of control rats labelled with DiR, and transferred into control rats through the left femoral vein. After 1 hour, the cardiopulmonary bypass (CPB) model was used. (C and D) The percentages and cell counts of $\mathrm{DiR}^{+} \mathrm{CD} 43^{\text {low }}$ and $\mathrm{CD} 43^{\text {high }}$ monocytes or macrophages in the lungs and the bronchoalveolar lavage fluid (BALF) were analysed by flow cytometry combined with haematometry at the indicated time points. Data are expressed as the mean \pm SEM of three individuals and are representative of three independent experiments.

splenectomy resulted in a more apparent decrease in CD $43^{\text {high }}$ than $\mathrm{CD} 43^{\text {low }}$ subsets, the spleen might be the main source of mature $\mathrm{CD} 43^{\text {high }}$ monocytes, while the majority of $\mathrm{CD} 43^{\text {low }}$ monocyte influx into the lungs is from the bone marrow.

Because of frequently complicated clinical situations, it is challenging to collect large amounts of samples from a single patient. We were still able to perform studies with samples from an adequate number of patients and obtain statistically meaningful data. However, samples from each patient were not sufficient to complete all studies. Thus, samples used between different experiments were not necessarily from the same group of patients. For the same reason, our study was limited by the small sample size, which may compromise our data interpretation due to less power in statistical analyses. Nevertheless, samples selected for all the studies were randomised to minimise potentially confounding factors. Importantly, data from our studies on the CPB rat model were consistent with the major findings from clinical samples.

Our study could provide possible novel targets for perioperative lung protection by manipulating monocyte subsets at different checkpoints, including exit from the reservoir, migration into the tissues, and differentiation into inflammatory subsets. Recently, this notion has been supported by the finding that angiotensin-converting enzyme inhibition (enalapril) could be beneficial in the treatment of myocardial infarction by preventing the release of monocytes from the splenic reservoir. ${ }^{40}$ More importantly, we also found that severe sepsis also results in similar changes to circulating monocytes in patients with severe 

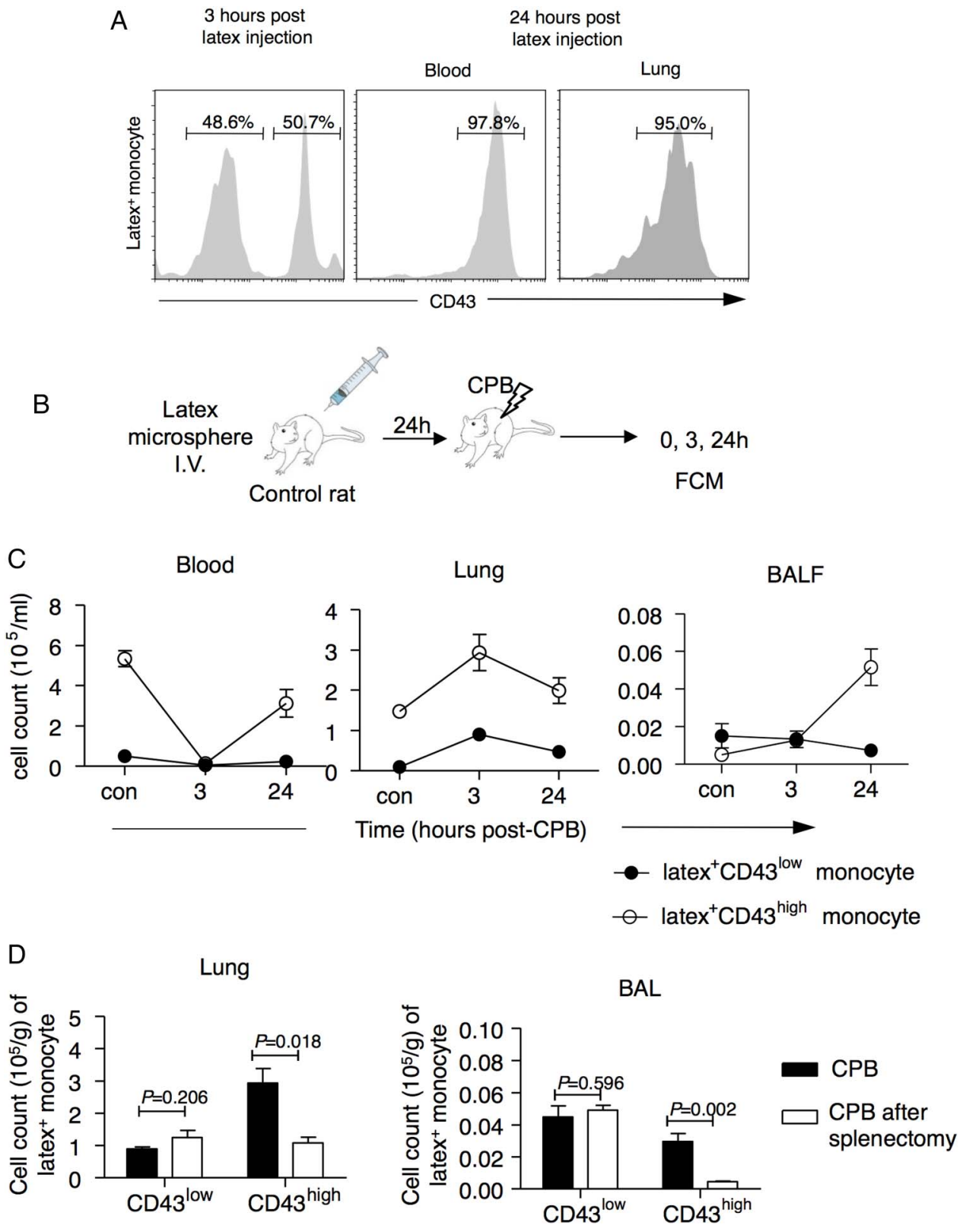

Figure $6 \mathrm{CD} 43^{\text {high }}$ monocytes migrated into the lung post cardiopulmonary bypass (CPB). (A) The mature CD43 ${ }^{\text {high }}$ monocytes were selectively labelled by fluorescent latex microspheres. Representative flow cytometric histogram of labelling rat CD43 ${ }^{\text {high }}$ monocytes. To label CD43 ${ }^{\text {high }}$ monocytes, anaesthetised rats were intravenously injected with Flouresbrite plain $0.5 \mu \mathrm{m}$ microspheres $(2.5 \%$ solids (wt/vol)) through the left femoral vein. After 24 hours, the CPB rat model was used. About half the monocytes were the CD43 ${ }^{\text {high }}$ subset at 3 hours after the latex injection, and more than $95 \%$ latex-positive cells in the blood and lung were the CD43 ${ }^{\text {high }}$ subset at 24 hours after injection. (B) The injection schedule for labelling of the rat CD43 $3^{\text {high }}$ monocyte subset in circulation is shown. (C) Numbers of latex-positive CD43 ${ }^{\text {low }}$ and latex-positive CD43 ${ }^{\text {high }}$ monocytes in the peripheral blood, the lung tissues, and the bronchoalveolar lavage fluid (BALF) of rats with CPB at different points were analysed by flow cytometry combined with haematometry ( $n=3$ at each time point). (D) The number of latex-positive monocytes in the lungs and the BALF at 3 hours post $C P B$ in rats with or without splenectomy. Data are expressed as the mean \pm SEM of three individuals and are representative of three independent experiments.

sepsis and septic shock (Han et al, unpublished data). Thus, new strategies based on monocyte manipulation might also be a promising therapeutic approach for a wider range of inflammatory diseases.

\footnotetext{
Author affiliations

'Department of Cardiopulmonary Bypass, Beijing Anzhen Hospital, Capital Medical University, Beijing, China

${ }^{2}$ Center for Cardiac Intensive Care, Beijing Anzhen Hospital, Capital Medical University, Beijing, China

${ }^{3}$ Institute of Infectious Diseases, Beijing Ditan Hospital, Capital Medical University, Beijing, China
}

${ }^{4}$ Beijing Key Laboratory of Emerging Infectious Diseases, Beijing, China ${ }^{5}$ Department of Gastroenterology, Renji Hospital, School of Medicine, Shanghai Jiaotong University, Shanghai, China

${ }^{6}$ Shanghai Institute of Digestive Disease, Shanghai, China

Contributors Study concept and design: $\mathrm{XH}$ and $\mathrm{HZ}$; acquisition of data: $\mathrm{ZX}, \mathrm{JH}$, $X H, J W, C J, Y H, X W, L S, X D$ and TL; analysis and interpretation of data: $Z X, J H, X H$, $\mathrm{HW}, \mathrm{GL}$ and JZ; first drafting of the manuscript: $\mathrm{ZX}, \mathrm{JH}$ and $\mathrm{XH}$; critical revision of the manuscript for important intellectual content: all authors; study supervision: $\mathrm{XH}$ and $\mathrm{HZ}$; data access and responsibility: $\mathrm{XH}$ and $\mathrm{HZ}$ had full access to all the data in the study and take responsibility for the integrity of the data and the accuracy of the data analysis and for the submission. 
Funding The authors received support from the National Natural Science Foundation of China (grant Nos. 81071587 to ZH, 81070203, 81270327 to HXT).

Competing interests None declared.

Patient consent Obtained.

Ethics approval All human blood samples were collected with written informed consent, and the study conformed to the tenets of the Declaration of Helsinki.

Provenance and peer review Not commissioned; externally peer reviewed.

\section{REFERENCES}

1 Edmunds LH. Cardiopulmonary bypass after 50 years. $N$ Engl J Med 2004;351:1603-6.

2 Park PK, Dalton HJ, Bartlett RH. Point: efficacy of extracorporeal membrane oxygenation in 2009 influenza $A(\mathrm{H} 1 \mathrm{~N} 1)$ : sufficient evidence? Chest 2010;138:776-8

3 Laffey JG, Boylan JF, Cheng DC. The systemic inflammatory response to cardiac surgery: implications for the anesthesiologist. Anesthesiology 2002;97:215-52.

4 Apostolakis E, Filos KS, Koletsis E, et al. Lung dysfunction following cardiopulmonary bypass. J Card Surg 2010;25:47-55.

5 Conti VR. Pulmonary injury after cardiopulmonary bypass. Chest 2001;119:2-4.

6 Kaul TK, Fields BL, Riggins LS, et al. Adult respiratory distress syndrome following cardiopulmonary bypass: incidence, prophylaxis and management. J Cardiovasc Surg (Torino) 1998:39:777-81.

7 Grichnik KP, D'Amico TA. Acute lung injury and acute respiratory distress syndrome after pulmonary resection. Semin Cardiothorac Vasc Anesth 2004:8:317-34.

8 Hadley JS, Wang JE, Michaels LC, et al. Alterations in inflammatory capacity and TLR expression on monocytes and neutrophils after cardiopulmonary bypass. Shock 2007;27:466-73.

9 Major TC, Brant DO, Reynolds MM, et al. The attenuation of platelet and monocyte activation in a rabbit model of extracorporeal circulation by a nitric oxide releasing polymer. Biomaterials 2010;31:2736-45.

10 Ingersoll MA, Platt AM, Potteaux S, et al. Monocyte trafficking in acute and chronic inflammation. Trends Immunol 2011;32:470-7.

11 Shi C, Pamer EG. Monocyte recruitment during infection and inflammation. Nat Rev Immunol 2011;11:762-74.

12 Gordon S, Taylor PR. Monocyte and macrophage heterogeneity. Nat Rev Immunol 2005;5:953-64.

13 Geissmann F, Manz MG, Jung S, et al. Development of monocytes, macrophages, and dendritic cells. Science 2010:327:656-61.

14 Auffray C, Sieweke MH, Geissmann F. Blood monocytes: development, heterogeneity, and relationship with dendritic cells. Annu Rev Immunol 2009;27:669-92.

15 Cros J, Cagnard N, Woollard K, et al. Human CD14dim monocytes patrol and sense nucleic acids and viruses via TLR7 and TLR8 receptors. Immunity 2010;33:375-86.

16 Wong KL, Yeap WH, Tai JJ, et al. The three human monocyte subsets: implications for health and disease. Immunol Res 2012;53:41-57.

17 Schmidl C, Renner K, Peter K, et al. Transcription and enhancer profiling in human monocyte subsets. Blood 2014;123:e90-9.

18 Ellery PJ, Tippett $\mathrm{E}$, Chiu YL, et al. The CD16+ monocyte subset is more permissive to infection and preferentially harbors HIV-1 in vivo. J Immunol 2007:178:6581-9.

19 Passos S, Carvalho LP, Costa RS, et al. Intermediate monocytes contribute to pathologic immune response in Leishmania braziliensis infections. J Infect Dis 2015;211:274-82.
20 Funderburg NT, Zidar DA, Shive C, et al. Shared monocyte subset phenotypes in HIV-1 infection and in uninfected subjects with acute coronary syndrome. Blood 2012;120:4599-608.

21 Ziegler-Heitbrock L, Ancuta P, Crowe S, et al. Nomenclature of monocytes and dendritic cells in blood. Blood 2010;116:e74-80.

22 Ziegler-Heitbrock L. Blood monocytes and their subsets: established features and open questions. Front Immunol 2015;6:423.

23 Kussick SJ, Wood BL. Using 4-color flow cytometry to identify abnormal myeloid populations. Arch Pathol Lab Med 2003;127:1140-7.

24 Shi G, Han J, Liu G, et al. Expansion of activated regulatory T cells by myeloid-specific chemokines via an alternative pathway in CSF of bacterial meningitis patients. Eur J Immunol 2014;44:420-30.

25 Tacke $F$, Ginhoux $F$, Jakubzick $C$, et al. Immature monocytes acquire antigens from other cells in the bone marrow and present them to $T$ cells after maturing in the periphery. J Exp Med 2006;203:583-97.

26 Nockher WA, Scherberich JE. Expanded CD14+ CD16+ monocyte subpopulation in patients with acute and chronic infections undergoing hemodialysis. Infect Immun 1998;66:2782-90.

27 Steiniger B, Stehling 0, Scriba A, et al. Monocytes in the rat: phenotype and function during acute allograft rejection. Immunol Rev 2001;184:38-44.

28 Yrlid U, Jenkins CD, MacPherson GG. Relationships between distinct blood monocyte subsets and migrating intestinal lymph dendritic cells in vivo under steady-state conditions. J Immunol 2006;176:4155-62.

29 Jia T, Pamer EG. Immunology. Dispensable but not irrelevant. Science 2009;325:549-50.

30 Swirski FK, Nahrendorf M, Etzrodt M, et al. Identification of splenic reservoir monocytes and their deployment to inflammatory sites. Science 2009;325:612-16.

31 Robbins CS, Chudnovskiy A, Rauch PJ, et al. Extramedullary hematopoiesis generates Ly-6C(high) monocytes that infiltrate atherosclerotic lesions. Circulation 2012;125:364-74.

32 Wang CT, Zhang L, Wu HW, et al. Doxycycline attenuates acute lung injury following cardiopulmonary bypass: involvement of matrix metalloproteinases. Int J Clin Exp Pathol 2014:7:7460-8.

33 Han J, Wang B, Han N, et al. CD14(high)CD16(+) rather than CD14(low)CD16(+) monocytes correlate with disease progression in chronic HIV-infected patients. J Acquir Immune Defic Syndr 2009;52:553-9.

34 Antonelli LR, Leoratti FM, Costa PA, et al. The CD14+CD16+ inflammatory monocyte subset displays increased mitochondrial activity and effector function during acute Plasmodium vivax malaria. PLoS Pathog 2014;10:e1004393.

35 Belge KU, Dayyani F, Horelt A, et al. The proinflammatory CD14+CD16+DR++ monocytes are a major source of TNF. J Immunol 2002;168:3536-42.

36 Jitschin R, Braun M, Buttner $M$, et al. CLL-cells induce IDOhi CD14+HLA-DRlo myeloid-derived suppressor cells that inhibit T-cell responses and promote TRegs. Blood 2014:124:750-60.

37 Filipazzi $P$, Valenti $R$, Huber $V$, et al. Identification of a new subset of myeloid suppressor cells in peripheral blood of melanoma patients with modulation by a granulocyte-macrophage colony-stimulation factor-based antitumor vaccine. J Clin Oncol 2007:25:2546-53.

38 Serbina NV, Jia T, Hohl TM, et al. Monocyte-mediated defense against microbia pathogens. Annu Rev Immunol 2008:26:421-52.

39 Goto Y, Hiramatsu Y, Ageyama N, et al. Cardiopulmonary bypass induces recruitment of bone marrow-derived leukocytes to the lungs in monkeys. Ann Thorac Surg 2014:97:617-22.

40 Leuschner F, Panizzi P, Chico-Calero I, et al. Angiotensin-converting enzyme inhibition prevents the release of monocytes from their splenic reservoir in mice with myocardial infarction. Circ Res 2010;107:1364-73. 